\title{
Mobile Robot Positioning: Sensors and Techniques
}

\section{J. Borenstein*}

The University of Michigan

Advanced Technologies Lab

1101 Beal Avenue

Ann Arbor, MI 48109-2110

e-mail: johannb@umich.edu

\section{H. R. Everett}

Naval Command, Control, and Ocean Surveillance Center

RDTEE Division 5303

271 Catalina Boulevard

San Diego, CA 92152-5001

\section{Feng}

The University of Michigan Advanced Technologies Lab 1101 Beal Avenue

Ann Arbor, MI 48109-2110

\section{Wehe}

The University of Michigan

Dept. of Nuclear Engineering and Radiological Sciences

239 Cooley Bldg.

Ann Arbor, MI 48109

Submitted April 1996, accepted and resubmitted

September 1996

*To whom all correspondence should be addressed. 


\begin{abstract}
Exact knowledge of the position of a vehicle is a fundamental problem in mobile robot applications. In search of a solution, researchers and engineers have developed a variety of systems, sensors, and techniques for mobile robot positioning. This article provides a review of relevant mobile robot positioning technologies. The article defines seven categories for positioning systems: (1) Odometry, (2) Inertial Navigation, (3) Magnetic Compasses, (4) Active Beacons, (5) Global Positioning Systems, (6) Landmark Navigation, and (7) Model Matching. The characteristics of each category are discussed and examples of existing technologies are given for each category. The field of mobile robot navigation is active and vibrant, with more great systems and ideas being developed continuously. For this reason the examples presented in this article serve only to represent their respective categories, but they do not represent a judgment by the authors. Many ingenious approaches can be found in the literature, although, for reasons of brevity, not all could be cited in this article. (c) 1997 John Wiley $\mathcal{E}$ Sons, Inc.
\end{abstract}

\footnotetext{
車两の正確な位置情報は、モービル・ロボットのアプリゲーションでは基本的な問題である。解決法 を探る研究の中で、研究者とエンジニアは、モービル・ロボットの位置決定に関して様々なシステム、セ ンサー、技術を開発してきた。この発表では、モービル・ロボットの位置決定に関連した技術の再検討 を行う。ここでは、位置決定システムの7つの分類を定義する。

1. 走行距離測定２. 慣性航法３.磁気コンパス４.アクティブ・ビーコン

5.グローバル位置決定システム 6. 境界標識 7.モデル・マッチング

各分類の特性について考察すると共に、それぞれに対して既存の技術の例を示す。

モービル・ロボットの運行に関する分野では、活発な研究と開発が行われており、より優れたシステム や理論が次々に開発されている。そのため、この発表で示す例は、単に各分類の特性を説明するた めのものであり、筆者の判断を示すためのものではない。文献から多くの巧妙な方法を見つけることが できるが、この発表では、簡略化のために一部分だけを引用している。
}

\section{INTRODUCTION}

This article surveys the state-of-the-art in sensors, systems, methods, and technologies that aim at finding a mobile robot's position in its environment. In surveying the literature on this subject, it became evident that a benchmark-like comparison of different approaches is difficult because of the lack of commonly accepted test standards and procedures. The research platforms used differ greatly, and so do the key assumptions used in different approaches. Further challenges arise from the fact that different systems are at different stages in their development. For example, one system may be commercially available, while another system, perhaps with better performance, has been tested only under a limited set of laboratory conditions. For these reasons we generally refrain from comparing or even judging the performance of different systems or techniques. Furthermore, we have not tested most of the systems and techniques, so the results and specifications given in this article are derived from the literature.

Finally, we should point out that a large body of literature related to navigation of aircraft, space craft, or even artillery addresses some of the problems found in mobile robot navigation. ${ }^{1,2}$ However, we have focused our survey only on literature pertaining directly to mobile robots. This is because sensor systems for mobile robots must usually be relatively small, lightweight, and inexpensive. Similarly we are not considering Automated Guided Vehicles (AGVs) in this article. AGVs use magnetic tape, buried guide wires, or painted stripes on the ground for guidance. These vehicles are thus not freely programmable, and they cannot alter their path in response to external sensory input (e.g., obstacle avoidance). However, the interested reader may find a survey of guidance techniques for AGVs in ref. 3.

Perhaps the most important result from surveying the literature on mobile robot positioning is that, to date, there is not truly elegant solution for the problem. The many partial solutions can roughly be categorized into two groups: relative and absolute position measurements. Because of the lack of a single good method, developers of mobile robots usually combine two methods, one from each group. The two groups can be further divided into the following seven categories: 
I: Relative position measurements (also called dead-reckoning)

1. Odometry

2. Inertial navigation

II: Absolute position measurements (referencebased systems)

3. Magnetic compasses

4. Active beacons

5. Global positioning systems

6. Landmark navigation

7. Model matching

\section{REVIEW OF SENSORS AND TECHNIQUES}

In this section we review some of the sensors and techniques used in mobile robot positioning. Examples of commercially available systems or well-documented research results will also be given.

\subsection{Odometry}

Odometry is the most widely used navigation method for mobile robot positioning; it provides good shortterm accuracy, is inexpensive, and allows very high sampling rates. However, the fundamental idea of odometry is the integration of incremental motion information over time, which leads inevitably to the unbounded accumulation of errors. Specifically, orientation errors will cause large lateral position errors, which increase proportionally with the distance traveled by the robot. Despite these limitations, most researchers agree that odometry is an important part of a robot navigation system and that navigation tasks will be simplified if odometric accuracy can be improved. For example, Cox, ${ }^{4}$ Byrne et al., ${ }^{5}$ and Chenavier and Crowley ${ }^{6}$ propose methods for fusing odometric data with absolute position measurements to obtain more reliable position estimation.

Odometry is based on simple equations, ${ }^{7}$ which hold true when wheel revolutions can be translated accurately into linear displacement relative to the floor. However, in the case of wheel slippage and some other more subtle causes, wheel rotations may not translate proportionally into linear motion. The resulting errors can be categorized into one of two groups: systematic errors and non-systematic errors. ${ }^{8}$ Systematic errors are those resulting from kinematic imperfections of the robot, for example, unequal wheel diameters or uncertainty about the exact wheelbase. Non-systematic errors are those that result from the interaction of the floor with the wheels, e.g., wheel slippage or bumps and cracks. Typically, when a mobile robot system is installed with a hybrid odometry / landmark navigation system, the density in which the landmarks must be placed in the environment is determined empirically and is based on the worst-case systematic errors. Such systems are likely to fail when one or more large non-systematic errors occur.

\subsubsection{Measurement of Odometry Errors}

One important but rarely addressed difficulty in mobile robotics is the quantitative measurement of odometry errors. Lack of well-defined measuring procedures for the quantification of odometry errors results in the poor calibration of mobile platforms and incomparable reports on odometric accuracy in scientific communications. To overcome this problem, Borenstein and Feng ${ }^{8}$ developed a method for quantitatively measuring systematic odometry errors and, to a limited degree, non-systematic odometry errors. This method, called University of Michigan Benchmark (UMBmark) requires that the mobile robot be programmed to follow a preprogrammed square path of $4 \times 4 \mathrm{~m}$ side-length and four on-the-spot 90degree turns. This run is to be performed five times in clockwise (cw) and five times in counter-clockwise (ccw) direction.

When the return position of the robot as computed by odometry is compared to the actual return position, an error plot similar to the one shown in Figure 1 will result. The results of Figure 1 can be interpreted as follows:

- The stopping positions after cw and ccw runs are clustered in two distinct areas.

- The distribution within the $\mathrm{cw}$ and ccw clusters are the result of non-systematic errors. However, Figure 1 shows that in an uncalibrated vehicle, traveling over a reasonably smooth concrete floor, the contribution of systematic errors to the total odometry error can be notably larger than the contribution of non-systematic errors.

The asymmetry of the centers of gravity in $\mathrm{cw}$ and $\mathrm{ccw}$ results from the dominance of two types of systematic errors, collectively called Type A and Type B. ${ }^{8}$ Type A errors are defined as orientation errors that reduce (or increase) the amount of rotation of the robot during the square path experiment in both 


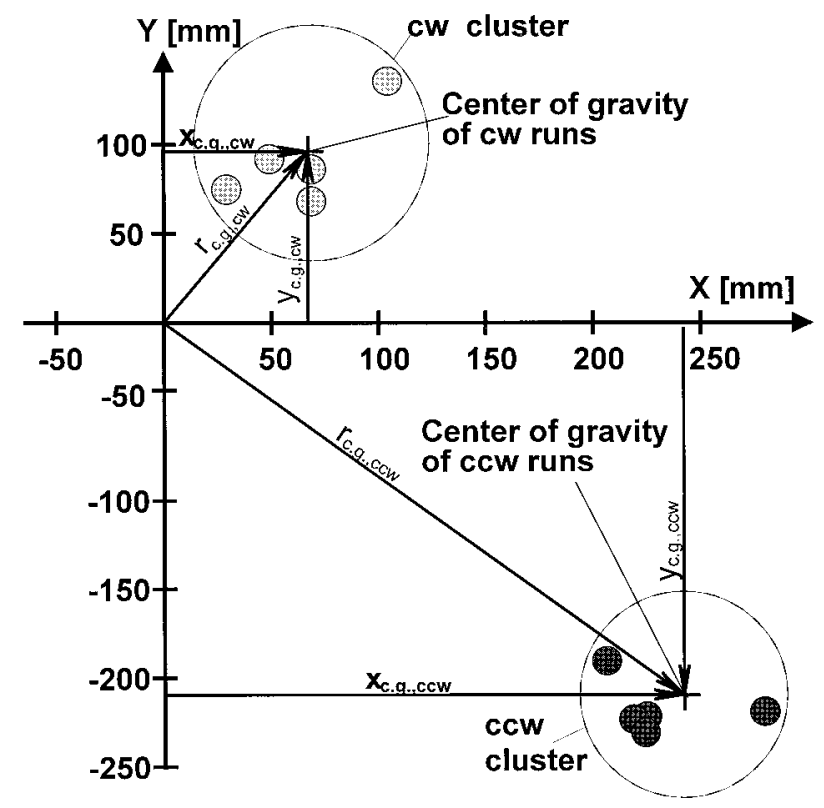

Figure 1. Typical results from running UMBmark (a square path run five times in $\mathrm{cw}$ and five times in ccw directions) with an uncalibrated TRC LabMate robot.

$\mathrm{Cw}$ and $\mathrm{ccw}$ direction. By contrast, Type B errors reduce (or increase) the amount of rotation when traveling in cw but have the opposite effect when traveling in ccw direction. One typical source for Type A errors is the uncertainty about the effective wheelbase; a typical source for Type B errors is unequal wheel diameters.

After conducting the UMBmark experiment a single numeric value that expresses the odometric accuracy (with respect to systematic errors) of the tested vehicle can be found from ${ }^{8}$ :

$$
E_{\max , \text { syst }}=\max \left(r_{c \cdot ., c, c w} ; r_{c . g, c, c c w}\right)
$$

where

$$
r_{c . g, c s}=\sqrt{\left(x_{c \cdot g \cdot, c c w}\right)^{2}+\left(y_{c \cdot g, c, c w}\right)^{2}}
$$

and

$$
r_{c . g, c c c w}=\sqrt{\left(x_{c \cdot g, c c c w}\right)^{2}+\left(y_{c . g, c c c w}\right)^{2}} .
$$

Based on the UMBmark test, Borenstein and Feng $^{8}$ developed a calibration procedure for reducing systematic odometry errors in differential drive vehicles. In this procedure the UMBmark test is performed five times in $\mathrm{cw}$ and $\mathrm{ccw}$ direction to find $x_{c ., y, c w}$ and $x_{c ., ., c c w}$. From a set of equations defined in ref. 8, two calibration constants are found that

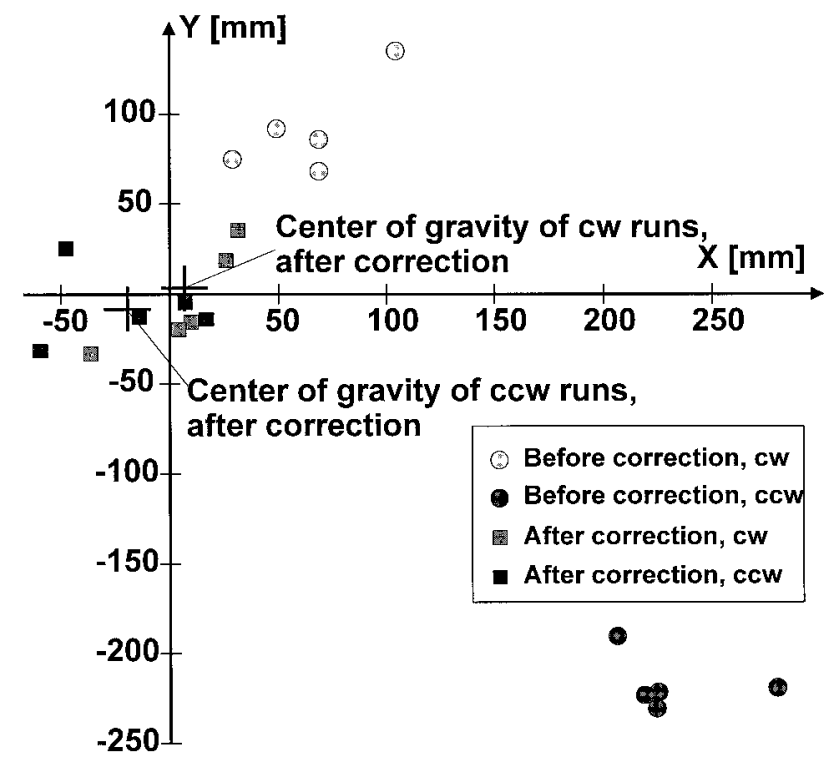

Figure 2. Position errors after completion of the bi-directional square-path experiment $(4 \times 4 \mathrm{~m})$.

can be included in the basic odometry computation of the robot. Application of this procedure to several differential-drive platforms resulted consistently in a 10- to 20 -fold reduction in systematic errors. Figure 2 shows the result of a typical calibration session, $E_{\text {max }, \text { sys }}$. The results for many calibration sessions with TRC's LabMate robots averaged $E_{\text {max }, \text { yys }}=330$ $\mathrm{mm}$ for uncalibrated vehicles and $E_{\max , \text { sys }}=24 \mathrm{~mm}$ after calibration.

\subsubsection{Measurement of Non-Systematic Errors}

Borenstein and Feng ${ }^{10}$ also proposed a method for measuring non-systematic errors. This method, called extended UMBmark, can be used for comparison of different robots under similar conditions, although the measurement of non-systematic errors is less useful because it depends strongly on the floor characteristics. However, using a set of well-defined floor irregularities and the UMBmark procedure, the susceptibility of a differential-drive platform to nonsystematic errors can be expressed. Experimental results from six different vehicles, which were tested for their susceptibility to non-systematic error by means of the extended UMBmark test, are presented in ref. 10.

Borenstein $^{11}$ developed a method for detecting and rejecting non-systematic odometry errors in mobile robots. With this method, two collaborating platforms continuously and mutually correct their nonsystematic (and certain systematic) odometry errors, even while both platforms are in motion. A video 


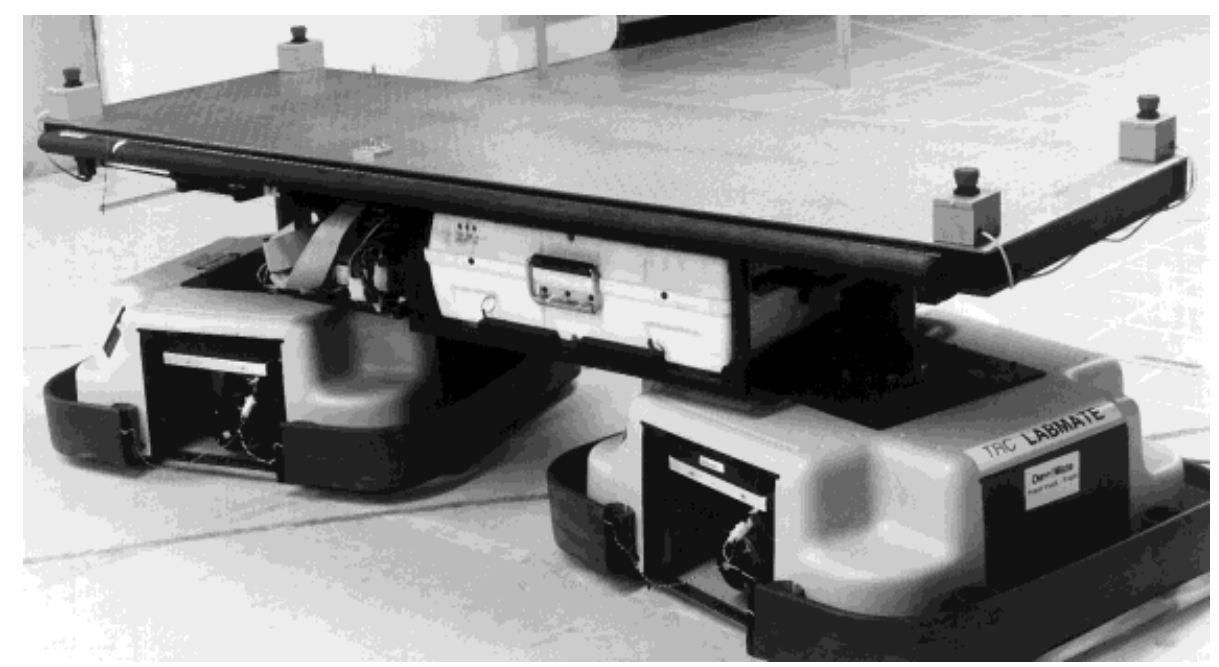

Figure 3. The OmniMate is a commercially available fully omni-directional platform. The two linked "trucks" mutually correct their odometry errors.

clip entitled "CLAPPER" showing this system in operation is included in refs. 12 and 20. A commercial version of this robot, shown in Figure 3, is now available under the name "OmniMate."13 Because of its internal odometry error correction, the OmniMate is almost completely insensitive to bumps, cracks, or other irregularities on the floor. ${ }^{9}$

\subsection{Inertial Navigation}

Inertial navigation uses gyroscopes and accelerometers to measure rate of rotation and acceleration, respectively. Measurements are integrated once (or twice, for accelerometers) to yield position. Inertial navigation systems have the advantage that they are self-contained, that is, they don't need external references. However, inertial sensor data drift with time because of the need to integrate rate data to yield position; any small constant error increases without bound after integration. Inertial sensors are thus mostly unsuitable for accurate positioning over an extended period of time.

\subsubsection{Accelerometers}

Test results from the use of accelerometers for mobile robot navigation have been generally poor. In an informal study at the University of Michigan it was found that there is a very poor signal-to-noise ratio at lower accelerations (i.e., during low-speed turns). Accelerometers also suffer from extensive drift, and they are sensitive to uneven ground because any disturbance from a perfectly horizontal position will cause the sensor to detect a component of the gravitational acceleration g. One low-cost inertial navigation system aimed at overcoming the latter problem included a tile sensor. ${ }^{14,15}$ The tilt information provided by the tilt sensor was supplied to the accelerometer to cancel the gravity component projecting on each axis of the accelerometer. Nonetheless, the results obtained from the tilt-compensated system indicate a position drift rate of 1 to $8 \mathrm{~cm} / \mathrm{s}(0.4$ to $3.1 \mathrm{in} / \mathrm{s})$, depending on the frequency of acceleration changes. This is an unacceptable error rate for most mobile robot applications.

\subsubsection{Gyroscopes}

Gyroscopes (also known as "rate gyros" or just "gy-

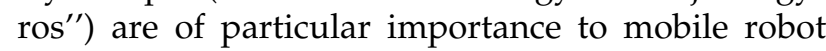
positioning because they can help compensate for the foremost weakness of odometry: in an odometrybased positioning method, any small momentary orientation error will cause a constantly growing lateral position error. For this reason it would be of great benefit if orientation errors could be detected and corrected immediately.

Until recently, highly accurate gyros were too expensive for mobile robot applications. For example, a high-quality inertial navigation system (INS) such as those found in a commercial airliner would have a typical drift of about 1850 meters (1 nautical mile) per hour of operation, and cost between $\$ 50 \mathrm{~K}$ and $\$ 70 \mathrm{~K} .{ }^{5}$ High-end INS packages used in ground applications have shown performance of better than $0.1 \%$ of distance traveled, but cost in the neighborhood of 


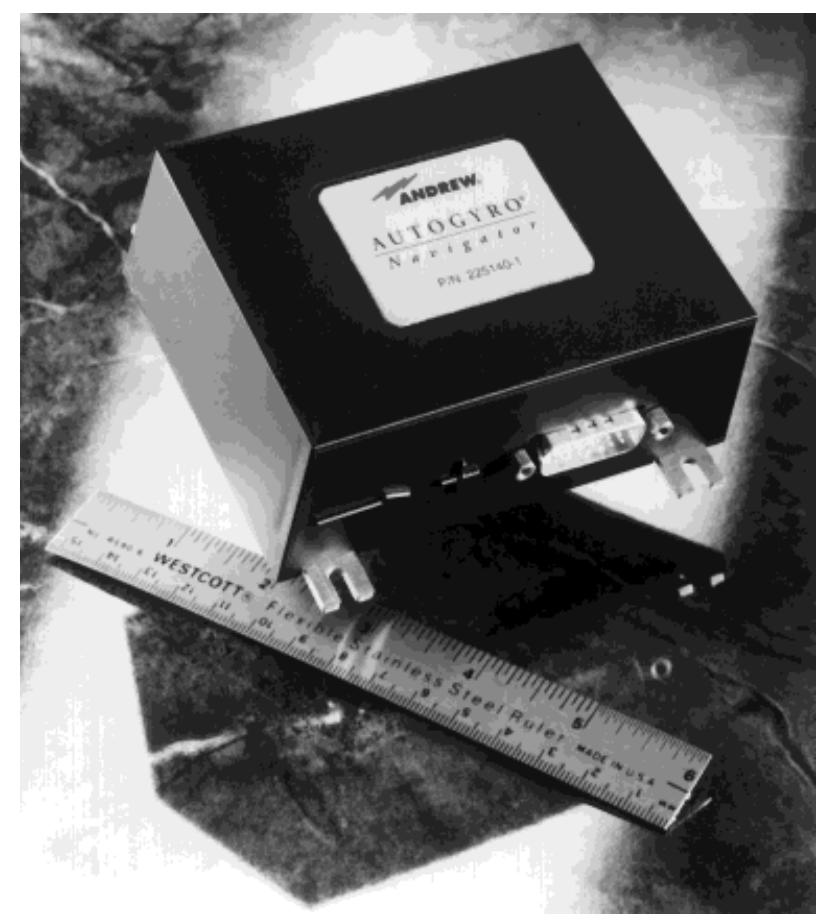

Figure 4. The Andrew AUTOGYRO Navigator (courtesy of Andrew Corporation ${ }^{17}$ ).

$\$ 100 \mathrm{~K}$ to $\$ 200 \mathrm{~K}$, while lower performance versions (i.e., $1 \%$ of distance traveled) run between $\$ 20 \mathrm{~K}$ to $\$ 50 \mathrm{~K} .^{16}$

However, very recently fiber-optic gyros (also called "laser gyros"), which are known to be very accurate, have fallen dramatically in price and have become a very attractive solution for mobile robot navigation.

One commercially available laser gyro is the " $\mathrm{Au}$ togyro Navigator" from Andrew Corp., ${ }^{17}$ shown in Figure 4. It is a single-axis interferometric fiber-optic gyroscope (see ref. 3 for technical details) based on polarization-maintaining fiber and precision fiberoptic gyroscope technology. Technical specifications for Andrew's most recent model, the Autogyro Navigator, are shown in Table I. This laser gyro costs under $\$ 1,000$ and is well suited for mobile robot navigation.

\subsection{Magnetic Compasses}

Vehicle heading is the most significant of the navigation parameters $(x, y$, and $\theta)$ in terms of its influence on accumulated dead-reckoning errors. For this reason, sensors that provide a measure of absolute heading are extremely important in solving the navigation needs of autonomous platforms. The magnetic compass is such a sensor. One disadvantage of any mag-
Table I. Selected specifications for the Andrew Autogyro Navigator (courtesy of Andrew Corporation ${ }^{17}$ ).

\begin{tabular}{|c|c|}
\hline Parameter & Value \\
\hline Input rotation rate & $\pm 100 \% \mathrm{~s}$ \\
\hline Instantaneous bandwidth & $100 \mathrm{~Hz}$ \\
\hline $\begin{array}{l}\text { Bias drift (at stabilized tem- } \\
\text { perature)-RMS }\end{array}$ & $\begin{array}{c}0.005 \% / \mathrm{hr} \mathrm{rms} \\
18 \% \text { sms }\end{array}$ \\
\hline \multicolumn{2}{|l|}{ Temperature range } \\
\hline Operating & -40 to $+75^{\circ} \mathrm{C}$ \\
\hline Storage & -50 to $+85{ }^{\circ} \mathrm{C}$ \\
\hline Warm up time & $1 \mathrm{~s}$ \\
\hline Size & $115 \times 90 \times 41 \mathrm{~mm}$ \\
\hline (excluding connector) & $4.5 \times 3.5 \times 1.6$ in \\
\hline \multirow{2}{*}{ Weight (total) } & $0.25 \mathrm{~kg}$ \\
\hline & $0.55 \mathrm{lb}$ \\
\hline Power analog & $<2 \mathrm{~W}$ \\
\hline Power digital & $<3 \mathrm{~W}$ \\
\hline
\end{tabular}

netic compass, however, is that the earth's magnetic field is often distorted near power lines or steel structures. ${ }^{5}$ This makes the straightforward use of geomagnetic sensors difficult for indoor applications.

Based on a variety of physical effects related to the earth's magnetic field, different sensor systems are available:

- Mechanical magnetic compasses.

- Fluxgate compasses.

- Hall-effect compasses.

- Magnetoresistive compasses.

- Magnetoelastic compasses.

The compass best suited for use with mobile robot applications is the fluxgate compass. When maintained in a level attitude, the fluxgate compass will measure the horizontal component of the earth's magnetic field, with the decided advantages of low power consumption, no moving parts, intolerance to shock and vibration, rapid start-up, and relatively low cost. If the vehicle is expected to operate over uneven terrain, the sensor coil should be gimbal-mounted and mechanically dampened to prevent serious errors introduced by the vertical component of the geomagnetic field.

\section{Example: KVH Fluxgate Compasses}

KVH Industries, Inc., Middletown, RI, offers a complete line of fluxgate compasses and related accessories, ranging from inexpensive units targeted for the individual consumer up through sophisticated systems intended for military applications. ${ }^{18}$ the C100 


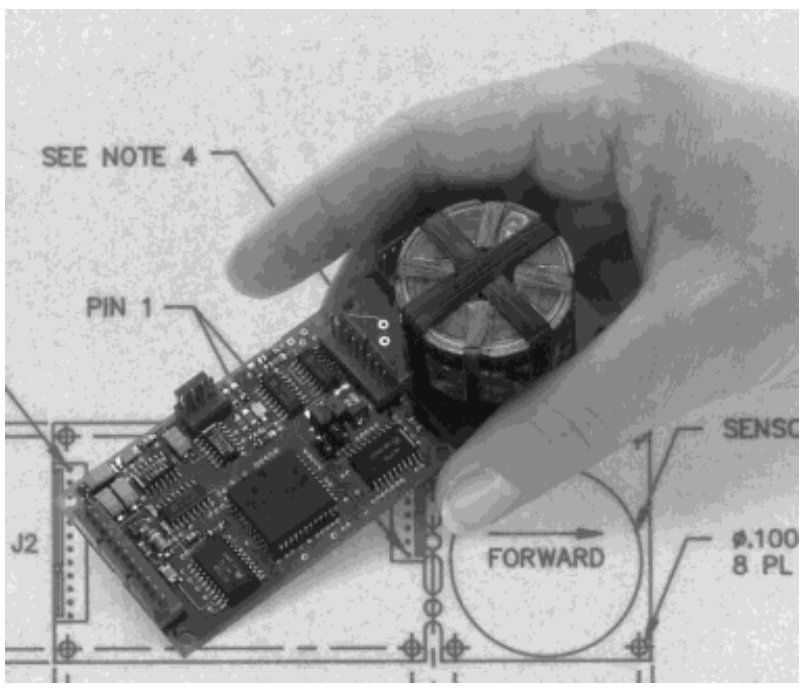

Figure 5. The C-100 fluxgate compass engine. (Reproduced from ref. 18 with permission from KVH Industries, Inc.)

COMPASS ENGINE shown in Figure 5 is a versatile, low-cost (less than \$700) developer's kit that includes a microprocessor-controlled stand-alone fluxgate sensor subsystem based on a two-axis toroidal ringcore sensor.

Two different sensor options are offered with the C100: (1) the SE-25 sensor, recommended for applications with a tilt range of \pm 16 degrees, and (2) the SE10 sensor, for applications anticipating a tilt angle of up to \pm 45 degrees.

The SE-25 sensor provides internal gimballing by floating the sensor coil in an inert fluid inside the lexan housing. The SE-10 sensor provides a 2 degreeof-freedom (DOF) pendulous gimbal in addition to the internal fluid suspension. The SE-25 sensor mounts on top of the sensor PC board, while the SE10 is suspended beneath it. The sensor PC board can be separated as much as $122 \mathrm{~cm}$ (48 in) from the detachable electronics PC board with an optional cable. Additional technical specifications are given in Table II.

\subsection{Active Beacons}

Active beacon navigation systems are the most common navigation aids on ships and airplanes, as well as on commercial mobile robot systems. Active beacons can be detected reliably and provide accurate positioning information with minimal processing. As a result, this approach allows high sampling rates and yields high reliability, but it does also incur high cost in installation and maintenance. Accurate
Table II. Technical specifications for the KVH C-100 fluxgate compass (Courtesy of KVH Industries ${ }^{18}$ ).

\begin{tabular}{|c|c|c|}
\hline Parameter & Value & Units \\
\hline Resolution & \pm 0.1 & $\circ$ \\
\hline Accuracy & \pm 0.5 & $\circ$ \\
\hline Repeatability & \pm 0.2 & $\circ$ \\
\hline \multirow[t]{2}{*}{ Size } & $46 \times 110$ & $\mathrm{~mm}$ \\
\hline & $1.8 \times 4.5$ & in. \\
\hline \multirow[t]{2}{*}{ Weight (total) } & 62 & $\mathrm{gr}$ \\
\hline & 2.25 & $\mathrm{OZ}$ \\
\hline Power: Current drain & 0.04 & A \\
\hline Supply voltage & $8-18$ or $18-28$ & $\mathrm{~V}$ \\
\hline
\end{tabular}

mounting of beacons is required for accurate positioning. Two different types of active beacon systems can be distinguished: trilateration and triangulation.

\subsubsection{Trilateration}

Trilateration is the determination of a vehicle's position based on distance measurements to known beacon sources. In trilateration navigation systems there are usually three or more transmitters mounted at known locations in the environment, and one receiver on board the robot. Conversely, there may be one transmitter on board, and the receivers are mounted on the walls. Using time-of-flight information, the system computes the distance between the stationary transmitters and the onboard receiver. Global Positioning Systems (GPSs), discussed in section 2.5, are an example of trilateration.

\subsubsection{Triangulation}

In this configuration there are three or more active transmitters mounted at known locations, as shown in Figure 6. A rotating sensor on board the robot registers the angles $\lambda_{1}, \lambda_{2}$, and $\lambda_{3}$ at which it "sees" the transmitter beacons relative to the vehicle's longitudinal axis. From these three measurements the unknown $x$ - and $y$-coordinates and the unknown vehicle orientation can be computed. One problem with this configuration is that in order to be seen at distances of, say, $20 \mathrm{~m}$ or more, the active beacons must be focused within a cone-shaped propagation pattern. As a result, beacons are not visible in many areas, a problem that is particularly grave because at least three beacons must be visible for triangulation.

Cohen and Koss ${ }^{19}$ performed a detailed analysis on three-point triangulation algorithms and ran computer simulations to verify the performance of differ- 


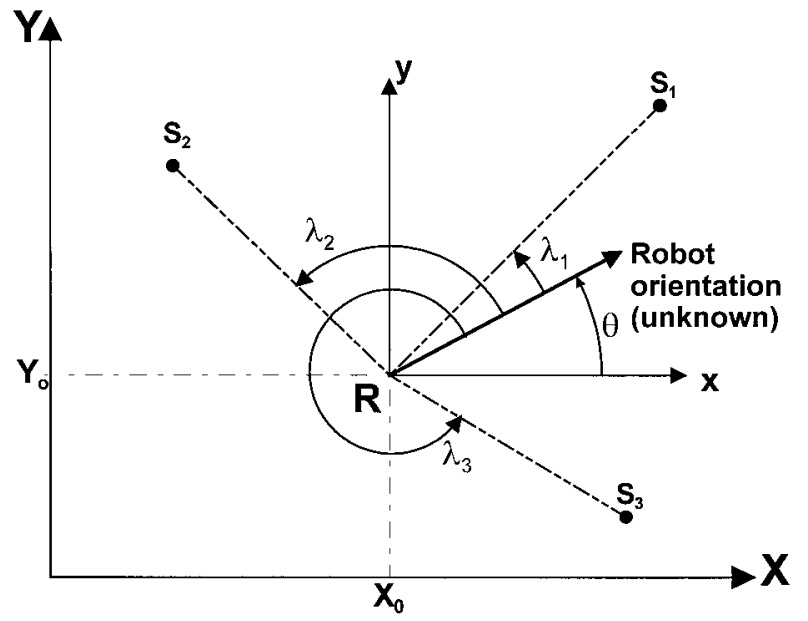

Figure 6. The basic triangulation problem: a rotating sensor head measures the three angles $\lambda_{1}, \lambda_{2}$, and $\lambda_{3}$ between the vehicle's longitudinal axes and the three sources $S_{1}, S_{2}$, and $\mathrm{S}_{3}$.

ent algorithms. The results are summarized as follows:

- The Geometric Triangulation method works consistently only when the robot is within the triangle formed by the three beacons. There are areas outside the beacon triangle where the geometric approach works, but these areas are difficult to determine and are highly dependent on how the angles are defined.

- The Geometric Circle Intersection method has large errors when the three beacons and the robot all lie on, or close to, the same circle.

- The Newton-Raphson method fails when the initial guess of the robot's position and orientation is beyond a certain bound.

- The heading of at least two of the beacons was required to be greater than 90 degrees. The angular separation between any pair of beacons was required to be greater than 45 degrees.

In summary, it appears that none of the above methods alone is always suitable, but an intelligent combination of two or more methods helps overcome the individual weaknesses.

\subsubsection{Specific Triangulation Systems}

Because of their technical maturity and commercial availability, optical triangulation-systems are widely used in mobile robotics applications. Typically these systems involve some type of scanning mechanism operating in conjunction with fixed-location references strategically placed at predefined locations within the operating environment. A number of variations on this theme are seen in practice ${ }^{3}$ : (a) scanning detectors with fixed active beacon emitters, (b) scanning emitter/detectors with passive retroreflective targets, (c) scanning emitter/detectors with active transponder targets, and (d) rotating emitters with fixed detector targets.

\section{Example: MTI Research CONAC ${ }^{\mathrm{TM}}$}

A similar type system using a predefined network of fixed-location detectors is made by MTI Research, Inc., Chelmsford, MA. ${ }^{19 a}$ MTI's Computerized Opto-electronic Nvaigation and Control (CONAC ${ }^{\mathrm{TM}}$ ) is a navigational referencing system employing a vehiclemounted laser unit called STRuctured Opto-electronic Acquisition Beacon (STROAB), as shown in Figure 7. The scanning laser beam is spread vertically to eliminate critical alignment, allowing the receivers, called Networked Opto-electronic Acquisition Datums (NOADs) (see Fig. 8), to be mounted at arbitrary heights as illustrated in Figure 9. Detection of incident illumination by a NOAD triggers a response over the network to a host PC, which in turn calculates the implied angles $\alpha 1$ and $\alpha 2$. An index sensor built into the STROAB generates a rotation reference pulse to facilitate heading measurement. Indoor accuracy is on the order of centimeters or millimeters, and better than $0.1^{\circ}$ for heading.

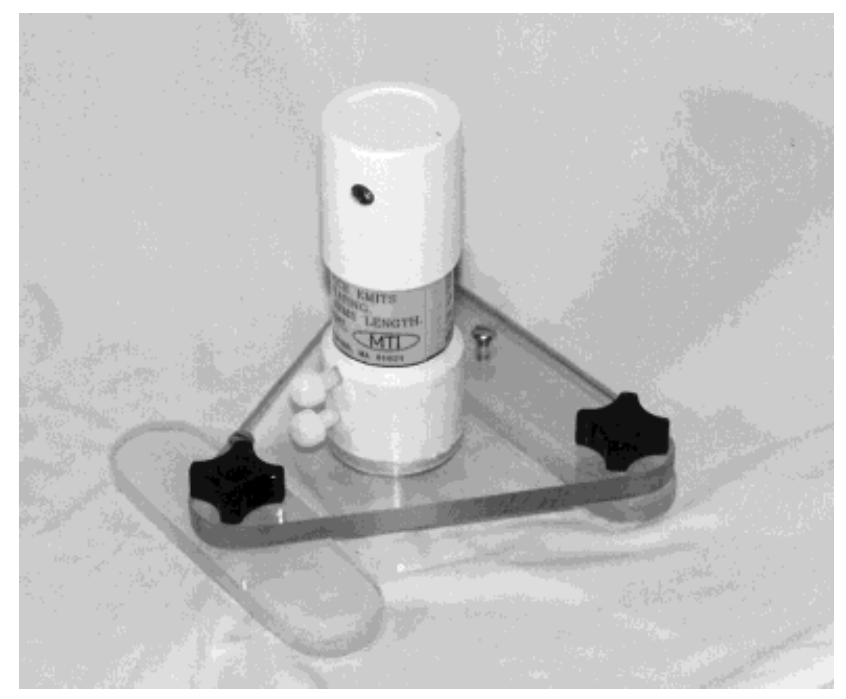

Figure 7. A single STROAB beams a vertically spread laser signal while rotating at 3,000 rpm (courtesy of MTI Research Inc. ${ }^{19}$ ). 


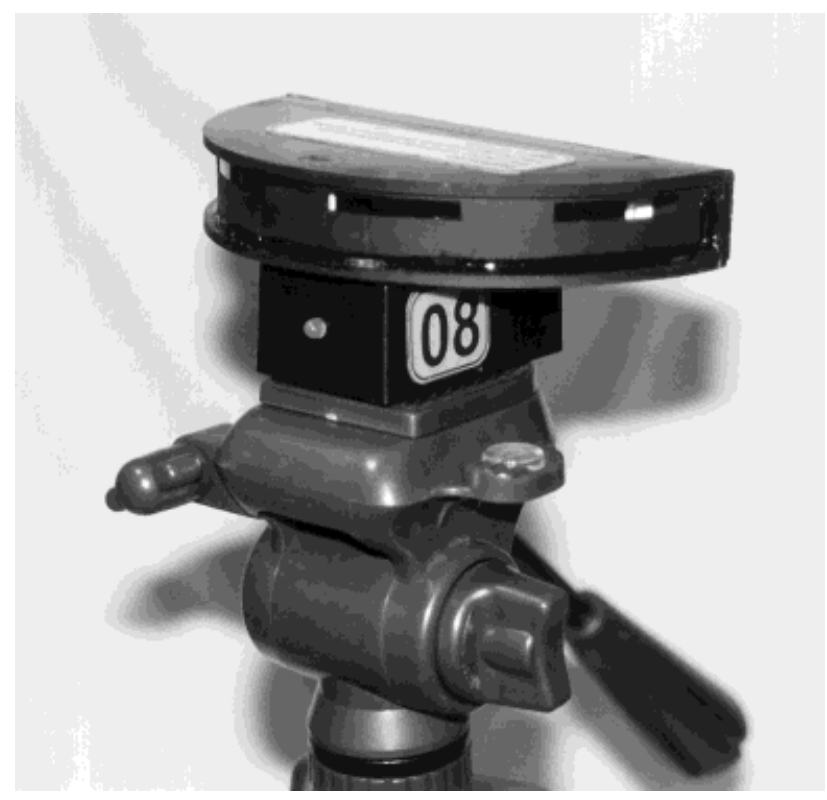

Figure 8. Stationary NOADs are located at known positions; at least two NOADs are networked and connected to a PC (courtesy of MTI Research Inc. ${ }^{19}$ ).

The reference NOADs are installed at known locations throughout the area of interest. STROAB acquisition range is sufficient to allow three NOADS to cover an area of $33,000 \mathrm{~m}^{2}$ if no interfering structures block the view. Additional NOADS may be employed to increase fault tolerance and minimize ambiguities when two or more robots are operating in close proximity. The optimal set of three NOADS is dynamically selected by the host PC, based on the current location of the robot and any predefined visual barriers. A short video clip showing the CONAC system in operation is included in ref. 20).

\subsection{Global Positioning Systems}

The Global Positioning System (GPS) is a revolutionary technology for outdoor navigation. GPS was developed as a Joint Services Program by the Department of Defense. The system comprises 24 satellites (including three spares) that transmit encoded RF signals. Using advanced trilateration methods, ground-based receivers can compute their position by measuring the travel time of the satellites' RF signals, which include information about the satellites' momentary location. Knowing the exact distance from the ground receiver to three satellites theoretically allows for calculation of receiver latitude, longitude, and altitude.

The US government deliberately applies small errors in timing and satellite position to prevent a hostile nation from using GPS in support of precision weapons delivery. This intentional degradation in positional accuracy to approximately $100 \mathrm{~m}(328 \mathrm{ft})$ worst case is termed selective availability (SA). ${ }^{21}$ Selective availability has been on continuously (with a few exceptions) since the end of Operation Desert Storm. It was turned off during the war from August 1990 until July 1991 to improve the accuracy of commercial handheld GPS receivers used by coalition ground forces. At another occasion (October 1992) SA was also turned off for a brief period while the Air Force was conducting tests. Byrne ${ }^{22}$ conducted tests at that time to com-

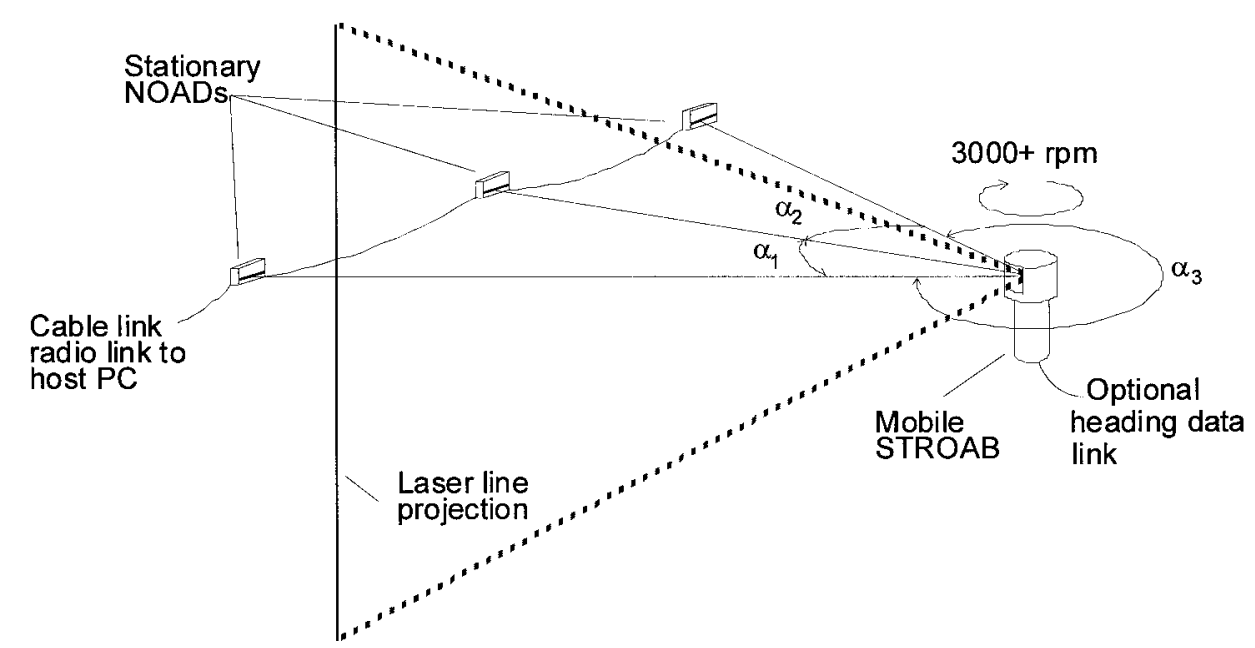

Figure 9. The CONAC ${ }^{\mathrm{TM}}$ system employs an onboard, rapidly rotating and vertically spread laser beam, which sequentially contacts the networked detectors (courtesy of MTI Research Inc. $\left.{ }^{19}\right)$. 


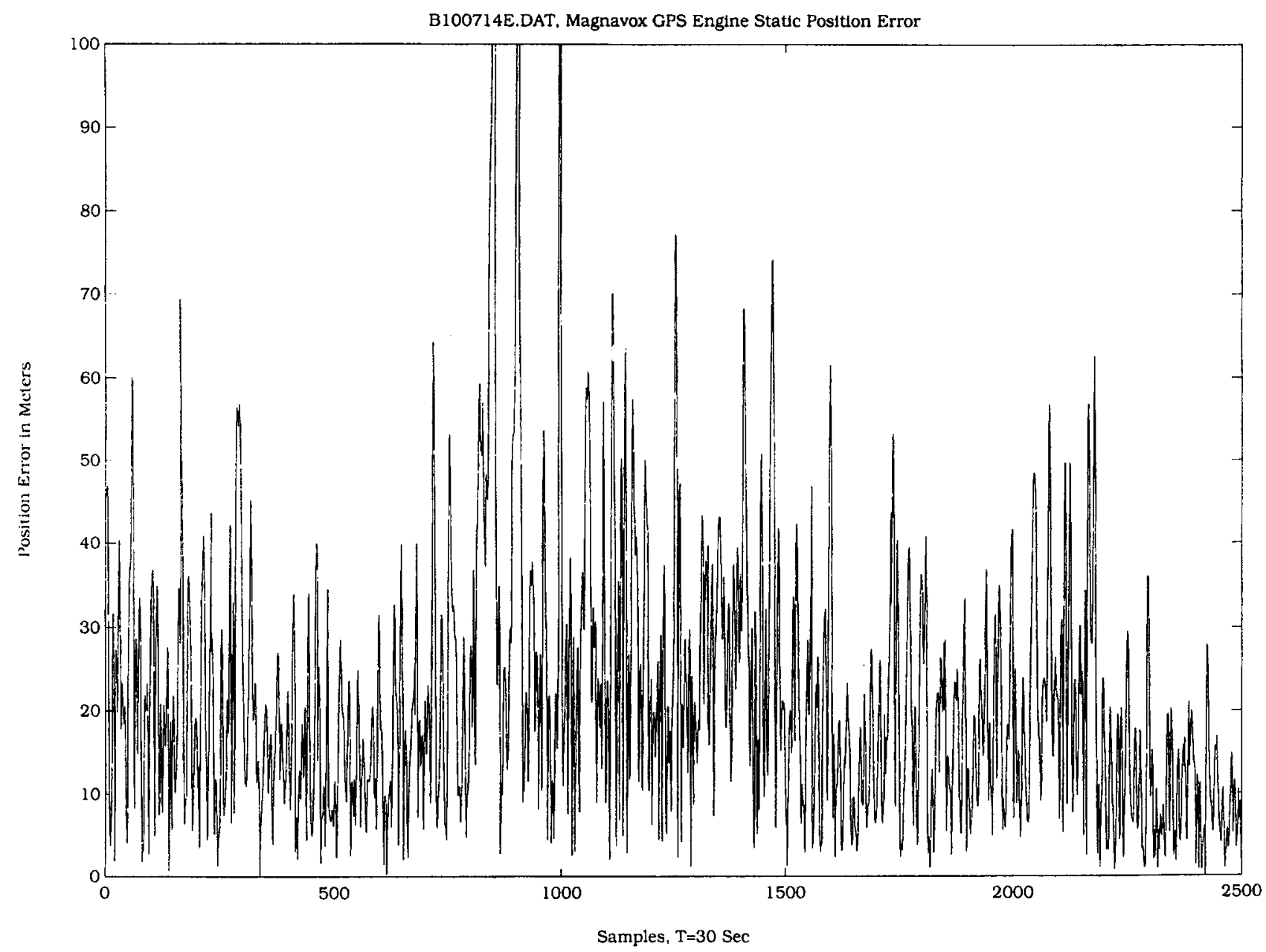

Figure 10. Typical GPS static position error with SA "On" (courtesy of Byrne, Sandia National Laboratories ${ }^{22}$ ).

pare the accuracy of GPS with SA turned on and off. The static measurements of the GPS error as a function of time (shown in Fig. 10) were taken before the October 1992 test, i.e., with SA "on" (note the slowly varying error in Fig. 10, which is caused by SA). By contrast, Figure 11 shows measurements from the October 1992 period when SA was briefly "off."

The effect of SA can be essentially eliminated through use of a practice known as differential GPS (DGPS). The concept is based on the premise that a second GPS receiver in fairly close proximity (i.e., within $10 \mathrm{~km}$, which is 6.2 miles) to the first will experience basically the same error effects when viewing the same reference satellites. If this second receiver is fixed at a precisely surveyed location, its calculated solution can be compared to the known position to generate a composite error vector representative of prevailing conditions in that immediate locale. This differential correction can then be passed to the first receiver to null out the unwanted effects, effectively reducing position error for commercial systems.

Many commercial GPS receivers are available with differential capability. This, together with the service of some local radio stations that make differential corrections available to subscribers of the service, ${ }^{23}$ makes the use of DGPS possible for many applications. Typical DGPS accuracies are around 4 to 6 $\mathrm{m}(13$ to $20 \mathrm{ft})$, with better performance seen as the distance between the mobile receivers and the fixed reference station is decreased. For example, the Coast Guard is in the process of implementing differential GPS in all major U.S. harbors, with an expected accuracy of around $1 \mathrm{~m}(3.3 \mathrm{ft}){ }^{24} \mathrm{~A}$ differential GPS system already in operation at $\mathrm{O}^{\prime}$ Hare International Airport in Chicago has demonstrated that aircraft and service vehicles can be located to $1 \mathrm{~m}(3.3 \mathrm{ft})$ in real- 


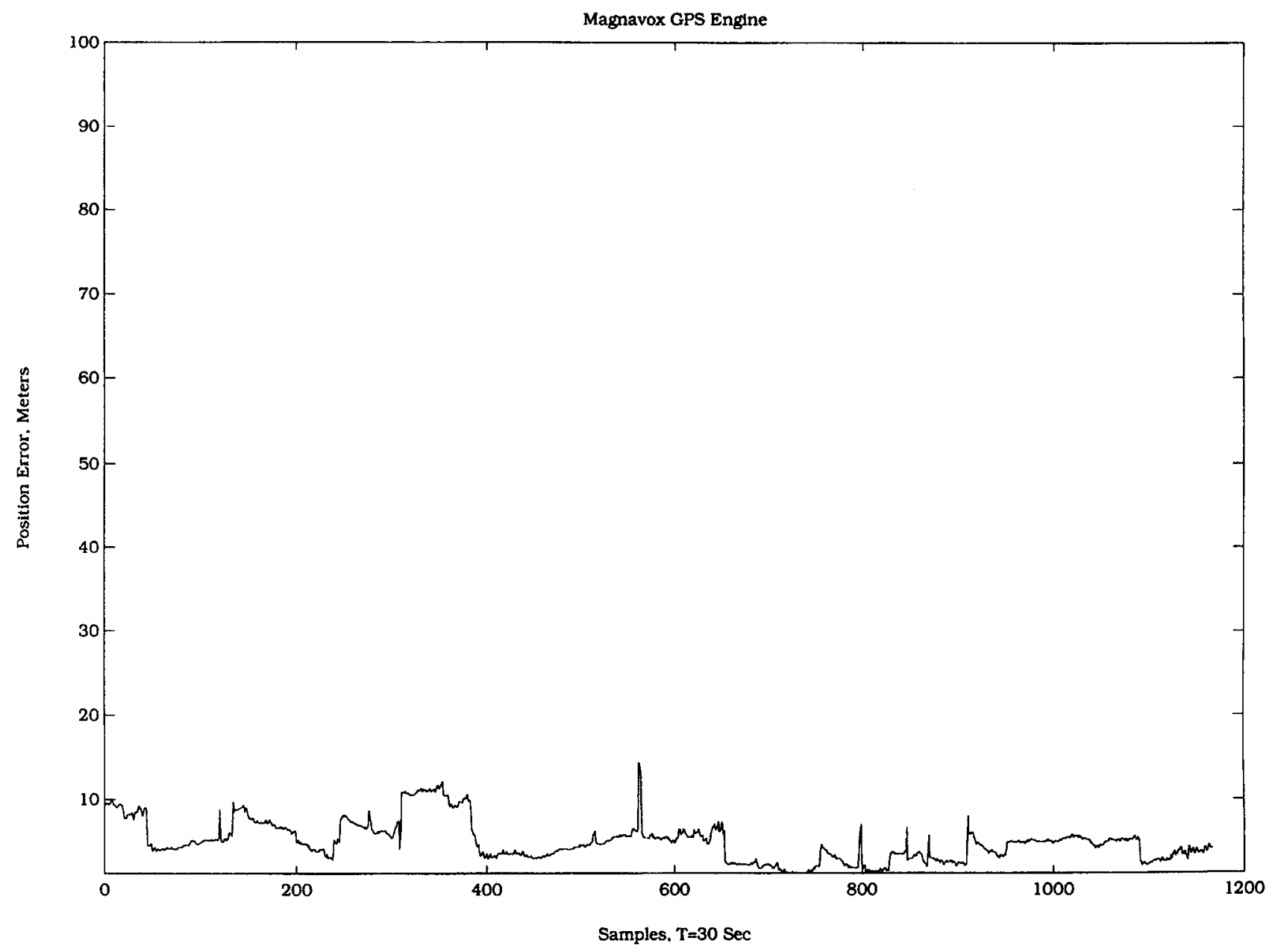

Figure 11. Typical GPS static position error with SA "Off" (courtesy of Byrne, Sandia National Laboratories ${ }^{22}$ ).

time, while moving. Surveyors use differential GPS to achieve centimeter accuracy, but this practice requires significant postprocessing of the collected data. ${ }^{22}$

In 1992 and 1993 Raymond H. Byrne ${ }^{22}$ at the Advanced Vehicle Development Department, Sandia National Laboratories, Albuquerque, New Mexico conducted a series of in-depth comparison tests with five different GPS receivers. Testing focused on receiver sensitivity, static accuracy, dynamic accuracy, number of satellites tracked, and time-to-first-fix. The more important parameters evaluated in this test, the static and dynamic accuracy, are summarized below for the Magnavox GPS Engine, a representative of the five receivers tested.

\section{Position Accuracy}

Static position accuracy was measured by placing the GPS receivers at a surveyed location and taking data for approximately 24 hours. The plots of the static position error for the Magnavox GPS Engine were shown in Figure 10. The mean and standard deviation $(\sigma)$ of the position error in this test was 22 $\mathrm{m}(72 \mathrm{ft})$ and $16 \mathrm{~m}(53 \mathrm{ft})$, respectively.

\section{Fractional Availability of Signals}

The dynamic test data was obtained by driving an instrumented van over different types of terrain. The various routes were chosen so that the GPS receivers would be subjected to a wide variety of obstructions. These include buildings, underpasses, signs, and foliage for the city driving. Rock cliffs and foliage were typical for the mountain and canyon driving. Large trucks, underpasses, highway signs, buildings, foliage, and small canyons were found on the interstate and rural highway driving routes.

The results of the dynamic testing are shown in 


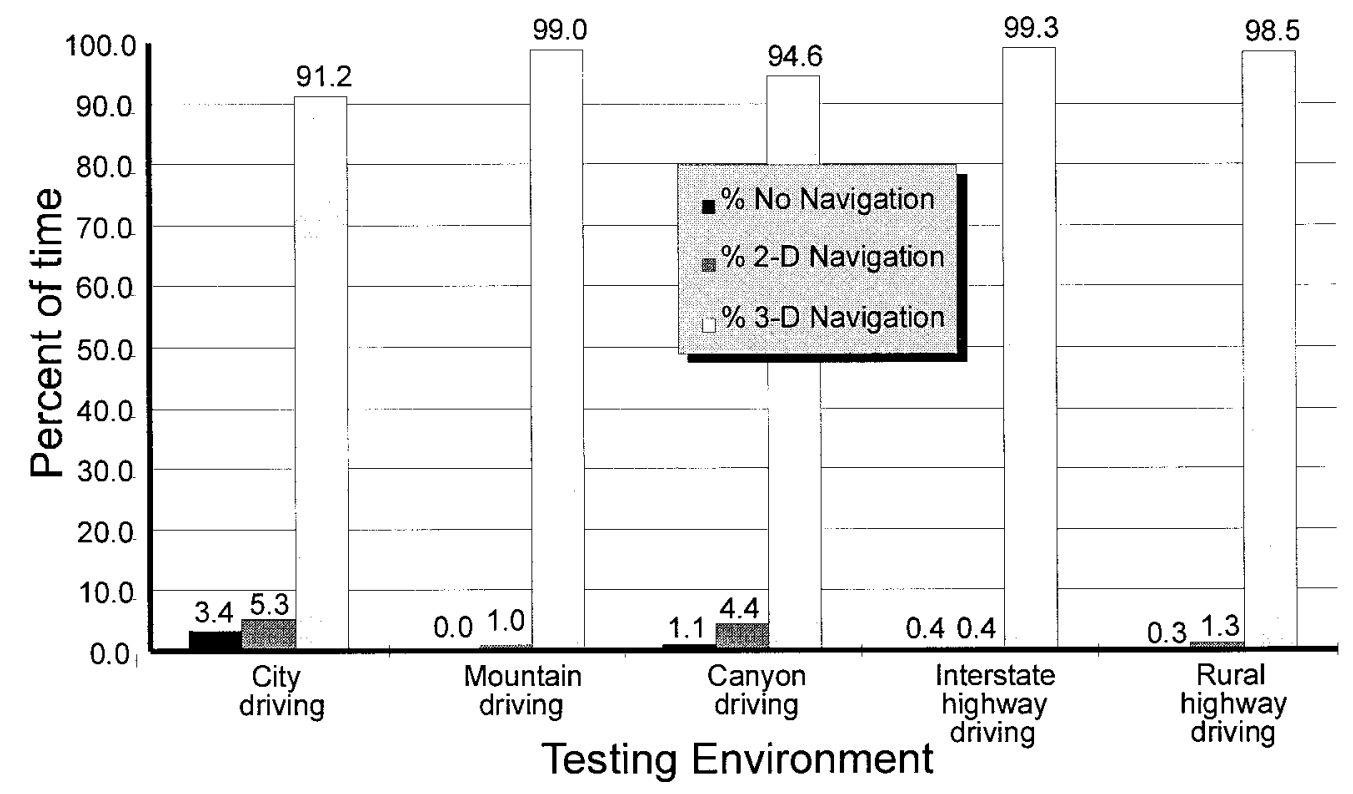

Figure 12. Summary of dynamic environment performance for the Magnavox GPS Engine (courtesy of Byrne, Sandia National Laboratories ${ }^{22}$ ).

Figure 12; the percentages have the following meaning:

No Navigation-Not enough satellites were in sight to permit positioning.

2-D Navigation-Enough satellites were in sight to determine the $x$ - and $y$-coordinates of the vehicle. 3-D Navigation-Optimal data available. System could determine $x-, y-$, and $z$-coordinates of the vehicle.

In summary one can conclude that GPS is a tremendously powerful tool for many outdoor navigation tasks. The problems associated with using GPS for mobile robot navigation are: (a) periodic signal blockage due to foliage and hilly terrain, (b) multipath interference, and (c) insufficient position accuracy for primary (stand-alone) navigation systems.

\subsection{Landmark Navigation}

Landmarks are distinct features that a robot can recognize from its sensory input. Landmarks can be geometric shapes (e.g., rectangles, lines, circles), and they may include additional information (e.g., in the form of bar-codes). In general, landmarks have a fixed and known position, relative to which a robot can localize itself. Landmarks are carefully chosen to be easy to identify; for example, there must be sufficient contrast relative to the background. Before a robot can use landmarks for navigation, the characteristics of the landmarks must be known and stored in the robot's memory. The main task in localization is then to recognize the landmarks reliably and to calculate the robot's position.

To simplify the problem of landmark acquisition it is often assumed that the current robot position and orientation are known approximately, so that the robot only needs to look for landmarks in a limited area. For this reason good odometry accuracy is a prerequisite for successful landmark detection.

Some approaches fall between landmark and map-based positioning (see section 2.7). They use sensors to sense the environment, and then extract distinct structures that serve as landmarks for navigation in the future.

Our discussion in this section addresses two types of landmarks: "artificial" and "natural" landmarks. It is important to bear in mind that "natural" landmarks work best in highly structured environments such as corridors, manufacturing floors, or hospitals. Indeed, one may argue that "natural" landmarks work best when they are actually man-made (as is the case in highly structured environments). For this reason, we shall define the terms "natural landmarks" and "artificial landmarks" as follows: natural landmarks are those objects or features that are already in the environment and have a function other than robot navigation; artificial landmarks are specially designed objects or markers that need to be placed in the environment with the sole purpose of enabling robot navigation. 


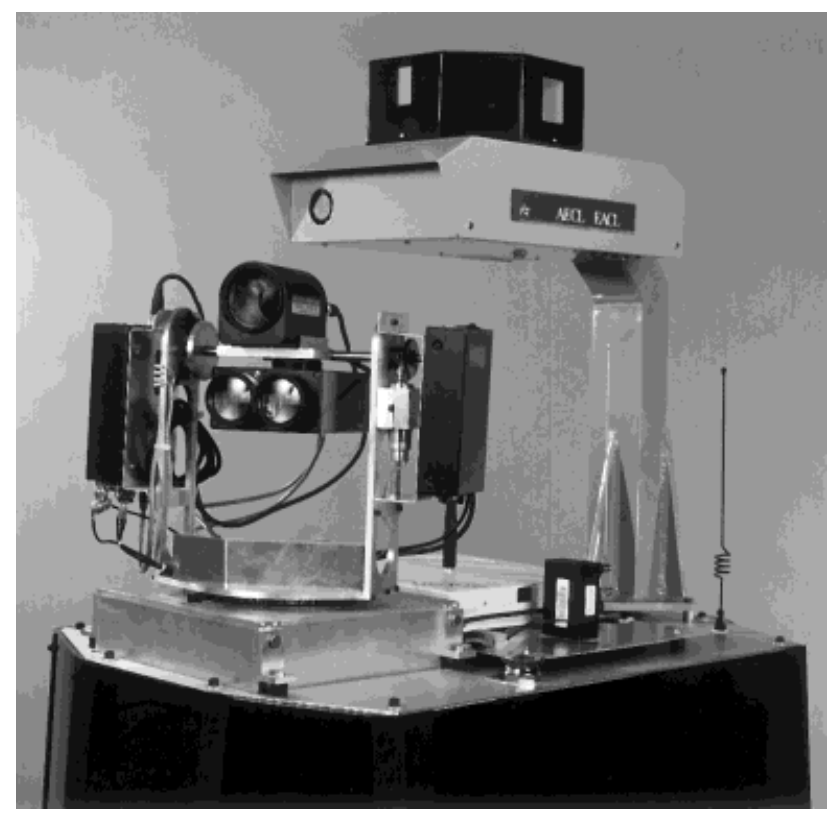

Figure 13. The ARK's natural landmark navigation system uses a CCD camera and a time-of-flight laser rangefinder to identify landmarks and to measure the distance between landmark and robot (courtesy of Atomic Energy of Canada Ltd.).

\subsubsection{Natural Landmarks}

The main problem in natural landmark navigation is to detect and match characteristic features from sensory inputs. The sensor of choice for this task is computer vision. Most computer vision-based natural landmarks are long vertical edges, such as doors, wall junctions, and ceiling lights (see TRC video clip in ref. 20).

When range sensors are used for natural landmark navigation, distinct signatures, such as those of a corner or an edge, or of long straight walls, are good feature candidates. The selection of features is important since it will determine the complexity in feature description, detection, and matching. Proper selection of features will also reduce the chances for ambiguity and increase positioning accuracy.

\section{Example: AECL's ARK Project}

One system that uses natural landmarks was developed jointly by the Atomic Energy of Canada Ltd (AECL) and Ontario Hydro Technologies with support from the University of Toronto and York University. ${ }^{25}$ This project aimed at developing a sophisticated robot system called the "Autonomous Robot for a Known Environment" (ARK).

The navigation module of the ARK robot is shown in Figure 13. The module consists of a custom- made pan-and-tilt table, a CCD camera, and an eyesafe IR spot laser rangefinder. Two VME-based cards, a single-board computer, and a microcontroller provide processing power. The navigation module is used to periodically correct the robot's accumulating odometry errors. The system uses natural landmarks such as alphanumeric signs, semi-permanent structures, or doorways. The only criteria used is that the landmark be distinguishable from the background scene by color or contrast.

The ARK navigation module uses an interesting hybrid approach: the system stores (learns) landmarks by generating a three-dimensional "gray-level surface" from a single training image obtained from the CCD camera. A coarse, registered range scan of the same field of view is performed by the laser rangefinder, giving depths for each pixel in the graylevel surface. Both procedures are performed from a known robot position. Later, during operation, when the robot is at an approximately known (from odometry) position within a couple of meters of the training position, the vision system searches for those landmarks that are expected to be visible from the robot's momentary position. Once a suitable landmark is found, the projected appearance of the landmark is computed. This expected appearance is then used in a coarse-to-fine normalized correlation-based matching algorithm that yields the robot's relative distance and bearing with regard to that landmark. With this procedure the ARK can identify different natural landmarks and measure its position relative to the landmarks. A video clip showing the ARK system in operation is included in ref. 20.

\subsubsection{Artificial Landmarks}

Detection is much easier with artificial landmarks, ${ }^{26}$ which are designed for optimal contrast. In addition, the exact size and shape of artificial landmarks are known in advance. Size and shape can yield a wealth of geometric information when transformed under the perspective projection.

Researchers have used different kinds of patterns or marks, and the geometry of the method and the associated techniques for position estimation vary accordingly. ${ }^{27}$ Many artificial landmark positioning systems are based on computer vision. We will not discuss these systems in detail, but will mention some of the typical landmarks used with computer vision. Fukui $^{28}$ used a diamond-shaped landmark and applied a least-squares method to find line segments in the image plane. Other systems use reflective material patterns and strobed light to ease the segmentation 
and parameter extraction. ${ }^{29,30}$ There are also systems that use active (i.e., LED) patterns to achieve the same effect. ${ }^{31}$

The accuracy achieved by the above methods depends on the accuracy with which the geometric parameters of the landmark images are extracted from the image plane, which in turn depends on the relative position and angle between the robot and the landmark. In general, the accuracy decreases with the increase in relative distance. Normally there is a range of relative angles in which good accuracy can be achieved, while accuracy drops significantly once the relative angle moves out of the "good" region.

There is also a variety of landmarks used in conjunction with non-vision sensors. Most often used are bar-coded reflectors for laser scanners. For example, work on the Mobile Detection Assessment and Response System (MDARS) ${ }^{3,32,33}$ uses retro-reflectors, and so does the commercially available system from Caterpillar on their Self-Guided Vehicle., ${ }^{54}$ The shape of these landmarks is usually unimportant. By contrast, a unique approach taken by Feng et al. ${ }^{35}$ used a circular landmark and applied an optical Hough transform to extract the parameters of the ellipse on the image plane in real time.

We summarize the characteristics of landmarkbased navigation as follows:

- Natural landmarks offer flexibility and require no modifications to the environment.

- Artificial landmarks are inexpensive and can have additional information encoded as patterns or shapes.

- The maximal effective distance between robot and landmark is substantially shorter than in active beacon systems.

- The positioning accuracy depends on the distance and angle between the robot and the landmark. Landmark navigation is rather inaccurate when the robot is further away from the landmark. A higher degree of accuracy is obtained only when the robot is near a landmark.

- Substantially more processing is necessary than with active beacon systems. In many cases onboard computers cannot process natural landmark algorithms quickly enough for real-time motion.

- Ambient conditions, such as lighting, can be problematic; in marginal visibility landmarks may not be recognized at all, or other objects in the environment with similar features can be mistaken for a legitimate landmark. This is a serious problem because it may result in a com- pletely erroneous determination of the robot's position.

- Landmarks must be available in the work environment around the robot.

- Landmark-based navigation requires an approximate starting location so that the robot knows where to look for landmarks. If the starting position is not known, the robot has to conduct a time-consuming search process. This search process may go wrong and may yield an erroneous interpretation of the objects in the scene.

- A database of landmarks and their location in the environment must be maintained.

- There is only limited commercial support for natural landmark-based techniques.

\subsection{Map-Based Positioning}

Map-based positioning, also known as "map matching," is a technique in which the robot uses its sensors to create a map of its local environment. This local map is then compared to a global map previously stored in memory. If a match is found, then the robot can compute its actual position and orientation in the environment. The pre-stored map can be a CAD model of the environment, or it can be constructed from prior sensor data. Map-based positioning is advantageous because it uses the naturally occurring structure of typical indoor environments to derive position information without modifying the environment. Also, with some of the algorithms being developed, map-based positioning allows a robot to learn a new environment and to improve positioning accuracy through exploration. Disadvantages of mapbased positioning are the stringent requirements for accuracy of the sensor map, and the requirement that there be enough stationary, easily distinguishable features that can be used for matching. Because of the challenging requirements currently, most work in map-based positioning is limited to laboratory settings and to relatively simple environments.

\subsubsection{Map Building}

There are two fundamentally different starting points for the map-based positioning process. Either there is a pre-existing map, or the robot has to build its own environment map. Rencken ${ }^{36}$ defined the map building problem as the following: "Given the robot's position and a set of measurements, what are the sensors seeing?" Obviously, the map-building ability of a robot is closely related to its sensing capacity. 
A problem related to map-building is "autonomous exploration. ${ }^{\prime 37}$ To build a map, the robot must explore its environment to map uncharted areas. Typically it is assumed that the robot begins its exploration without having any knowledge of the environment. Then, a certain motion strategy is followed that aims at maximizing the amount of charted area in the least amount of time. Such a motion strategy is called "exploration strategy," and it depends strongly on the kind of sensors used. One example for a simple exploration strategy based on a lidar sensor is given by Edlinger and Puttkamer. ${ }^{38}$

Many researchers believe that no single sensor modality alone can adequately capture all relevant features of a real environment. To overcome this problem, it is necessary to combine data from different sensor modalities, a process known as sensor fusion. For example, Buchberger et al. ${ }^{39}$ and Jorg ${ }^{40,41}$ developed a mechanism that utilizes heterogeneous information obtained from a laser-radar and a sonar system to construct reliable and complete world models. Sensor fusion is an active research area, and the literature is replete with techniques that combine various types of sensor data.

\subsubsection{Map Matching}

One of the most important and challenging aspects of map-based navigation is map matching, i.e., establishing the correspondence between a current local map and a stored global map..$^{42}$ Work on map matching in the computer vision community is often focused on the general problem of matching an image of arbitrary position and orientation relative to a model (e.g., ref. 27). In general, matching is achieved by first extracting features, followed by determination of the correct correspondence between image and model features, usually by some form of constrained search. ${ }^{4}$ A discussion of two different classes of matching algorithms, "icon-based" and "feature-based," is given in ref. 43.

\section{Example: University of Kaiserslautern's Angle Histogram}

A simple but apparently very effective method for map-building was developed by Hinkel and Knieriemen ${ }^{44}$ from the University of Kaiserslautern, Germany. This method, called the "Angle Histogram," used an in-house developed lidar. A typical scan from this lidar is shown in Figure 14.

The angle histogram method works as follows. First, a 360-degree scan of the room is taken with the lidar, and the resulting "hits" are recorded in a map.

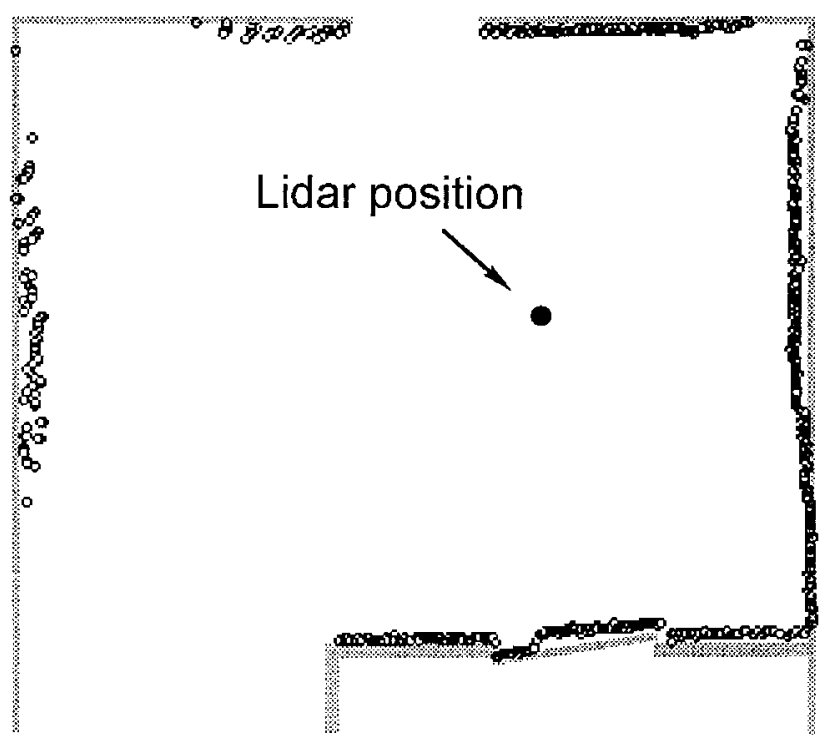

Figure 14. A typical scan of a room, produced by the University of Kaiserslautern's in-house developed lidar system (courtesy of the University of Kaiserslautern).

Then the algorithm measures the relative angle $\delta$ between any two adjacent hits (see Fig. 15). After compensating for noise in the readings (caused by the inaccuracies in position between adjacent hits), the angle histogram shown in Figure 16(a) can be built. The uniform direction of the main walls are clearly visible as peaks in the angle histogram. Computing the histogram modulo $\pi$ results in only two main peaks: one for each pair of parallel walls. This algorithm is very robust with regard to openings in the walls, such as doors and windows, or even cabinets lining the walls.

After computing the angle histogram, all angles of the hits can be normalized, resulting in the representation shown in Figure 16(b). After this transformation, two additional histograms, one for the $x$ - and one for the $y$-direction can be constructed. This time, peaks show the distance to the walls in $x$ - and $y$ -

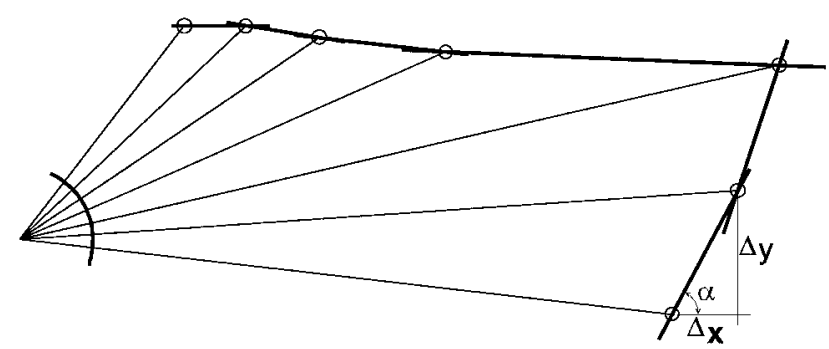

Figure 15. Calculating angles for the angle histogram (courtesy of Weiss ${ }^{45}$ ). 

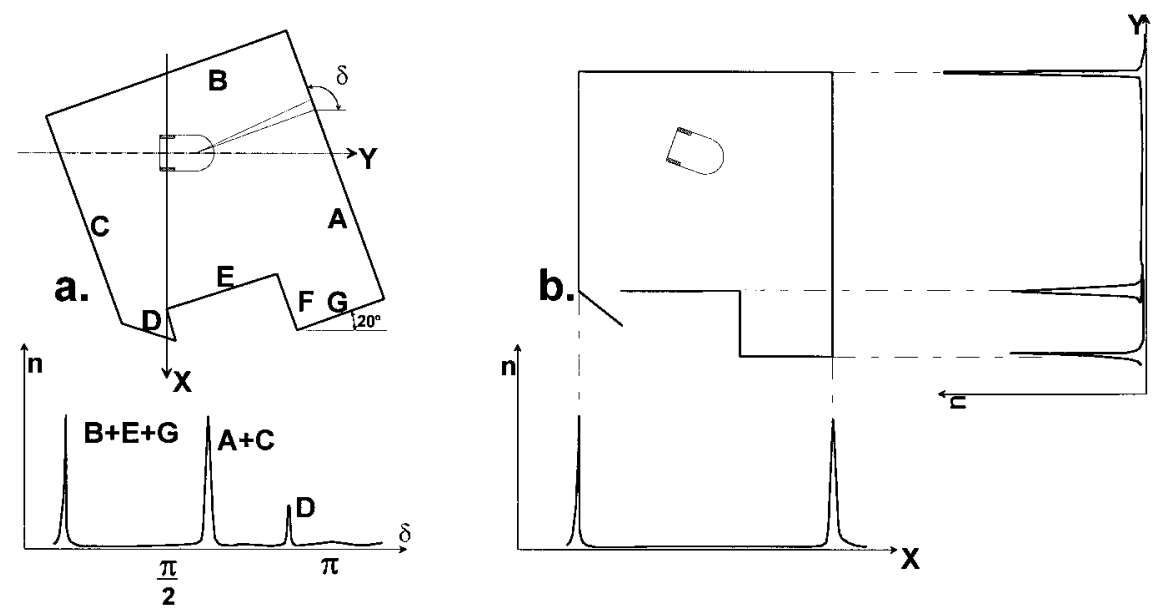

Figure 16. Readings from a rotating laser scanner generate the contours of a room. (a) the angle histogram allows the robot to determine its orientation relative to the walls; (b) after normalizing the orientation of the room relative to the robot, an $x-y$ histogram can be built from the same data points (adapted from Hinkel and Knieriemen ${ }^{44}$ with permission).

direction. Hinkel and Knieriemen's original algorithms have been further refined over the past years (e.g., Weiss et al. ${ }^{45}$ ) and the Angle Histogram method is now said to yield a reliable accuracy of $0.5^{\circ}$ ).

\section{Example 2: Siemens' Roamer}

Rencken $^{36,37}$ at the Siemens Corporate Research and Development Center in Munich, Germany, has made substantial contributions toward solving the boot strap problem resulting from the uncertainty in position and environment. This problem exists when a robot must move around in an unknown environment, with uncertainty in its odometry-derived position. For example, when building a map of the environment, all measurements are necessarily relative to the carrier of the sensors (i.e., the mobile robot). Yet, the position of the robot itself is not known exactly, because of the errors accumulating in odometry.

Rencken addresses the problem as follows: to represent features "seen" by its 24 ultrasonic sensors, the robot constructs hypotheses about these features. To account for the typically unreliable information from ultrasonic sensors, features can be classified as hypothetical, tentative, or confirmed. Once a feature is confirmed, it is used for constructing the map. Before the map can be updated, however, every new data point must be associated with either a plane, a corner, or an edge (or some variations of these features). Rencken devises a "hypothesis tree," which is a data structure that allows tracking of different hypotheses until a sufficient amount of data has been accumulated to make a final decision.

\section{CONCLUSIONS}

This article presented an overview of existing sensors and techniques for mobile robot positioning. We defined seven categories for these sensors and techniques, but obviously other ways for organizing the subject are possible. The foremost conclusion we could draw from reviewing the vast body of literature was that for indoor mobile robot navigation no single, elegant solution exists. For outdoor navigation GPS is promising to become the universal navigation solution for almost all automated vehicle systems.

Unfortunately, an indoor equivalent to GPS is difficult to realize because none of the currently existing RF-based trilateration systems work reliably indoors. If line-of sight between stationary and onboard components can be maintained, then RF-based solutions can work indoors as well. However, in that case optical components using triangulation are usually less expensive. The market seems to have adopted this thought some time ago, as can be seen in the relatively large number of commercially available navigation systems that are based on optical triangulation (as discussed in section 2.4.3).

Despite the variety of powerful existing systems and techniques, we believe that mobile robotics is still in need for a particularly elegant and universal indoor navigation method. Such a method will likely bring scientific recognition and commercial success to its inventor. 
Table A-1. Tabular comparison of positioning systems.

\begin{tabular}{|c|c|c|c|c|}
\hline \multirow{2}{*}{$\begin{array}{l}\text { System \& } \\
\text { description }\end{array}$} & \multicolumn{2}{|c|}{ Accuracy } & \multirow{2}{*}{$\begin{array}{l}\text { Effective } \\
\text { range }\end{array}$} & \multirow[b]{2}{*}{ Ref. no. } \\
\hline & Position [mm] & Orientation $\left[{ }^{\circ}\right]$ & & \\
\hline $\begin{array}{l}\text { Odometry on TRC LabMate, after } \\
\text { UMBmark calibration. Wheel-encoder } \\
\text { resolution: } 0.012 \mathrm{~mm} \text { linear travel per } \\
\text { pulse }\end{array}$ & $\begin{array}{l}4 \times 4 \text { meters square path: } \\
\text { smooth floor: } 30 \mathrm{~mm} \\
10 \text { bumps: } 500 \mathrm{~mm}\end{array}$ & $\begin{array}{l}\text { Smooth floor: } \\
1-2^{\circ} \\
\text { With } 10 \text { bumps: } 8^{\circ}\end{array}$ & Unlimited & 8 \\
\hline $\begin{array}{l}\text { CLAPPER and OmniMate: } \\
\text { Dual-drive robot with internal correction } \\
\text { of odometry. Made from two TRC Lab- } \\
\text { Mates, connected by compliant linkage. } \\
\text { Uses } 2 \text { abs. rotary encoders, } 1 \text { linear en- } \\
\text { coder. }\end{array}$ & $\begin{array}{l}4 \times 4 \text { m square path: } \\
\text { smooth floor: } \sim 20 \mathrm{~mm} \\
10 \text { bumps: } \sim 40 \mathrm{~mm}\end{array}$ & $\begin{array}{l}\text { Smooth floor: }<1^{\circ} \\
10 \text { bumps: }<1^{\circ}\end{array}$ & Unlimited & 9 \\
\hline $\begin{array}{l}\text { Complete inertial navigation system in- } \\
\text { cluding ENV-O5S Gyrostar solid state } \\
\text { rate gyro, START solid state gyro, triax- } \\
\text { ial linear accelerometer and } 2 \text { inclinom- } \\
\text { eters }\end{array}$ & $\begin{array}{l}\text { Position drift rate: } \\
1-8 \mathrm{~cm} / \mathrm{s} \text { depending on } \\
\text { frequency of accelera- } \\
\text { tion change }\end{array}$ & $\begin{array}{l}\text { Drift: } 5-0.25^{\circ} / \mathrm{s} \\
\text { After compensation } \\
\quad \text { drift } 0.0125^{\circ} / \mathrm{s}\end{array}$ & Unlimited & 14,15 \\
\hline $\begin{array}{l}\text { Andrew Autogyro and Autogyro Naviga- } \\
\text { tor. Quoted minimum detectable rota- } \\
\text { tion rate: } \pm 0.02^{\circ} / \mathrm{s} \text {. Actual minimum } \\
\text { detectable rate limited by deadband } \\
\text { after A / D conversion: } 0.0625^{\circ} / \mathrm{s} \text {. Cost: } \\
\$ 1000\end{array}$ & Not applicable & Drift: $0.005^{\circ} / \mathrm{s}$ & Unlimited & 17 \\
\hline $\begin{array}{l}\text { KVH Fluxgate Compass. Includes micro- } \\
\text { processor-controlled fluxgate sensor } \\
\text { subsystem. Cost }<\$ 700\end{array}$ & Not applicable & $\begin{array}{l}\text { Resolution: } \pm 0.5^{\circ} \\
\text { Accuracy: } \pm 0.5^{\circ} \\
\text { Repeatability: } \pm 0.2^{\circ}\end{array}$ & Unlimited & 18 \\
\hline $\begin{array}{l}\text { CONAC }^{\mathrm{TM}} \text { (computer- } \\
\text { ized opto-electronic } \\
\text { navigation and } \\
\text { control). } \\
\text { Cost: } \$ 6,000 \text {. }\end{array}$ & $\begin{array}{l}\text { Indoor } \pm 1.3 \mathrm{~mm} \\
\text { Outdoor } \pm 5 \mathrm{~mm}\end{array}$ & $\begin{array}{l}\text { Indoor and out- } \\
\text { door } \pm 0.05^{\circ}\end{array}$ & $>100 \mathrm{~m}$ & $19 a$ \\
\hline $\begin{array}{l}\text { Global Positioning Sys- } \\
\text { tems (GPS). } \\
\text { Cost: } \$ 1,000-\$ 5,000 \text {. }\end{array}$ & $\begin{array}{l}\text { Order of } 20 \mathrm{~m} \text { during } \\
\text { motion, order of centi- } \\
\text { meters when standing } \\
\text { for minutes }\end{array}$ & Not applicable & Unlimited & $\begin{array}{l}\text { Various } \\
\text { vendors }\end{array}$ \\
\hline Landmark Navigation & $<5 \mathrm{~cm}$ & $<1 \mathrm{deg}$ & $\sim 10 \mathrm{~m}$ & $\begin{array}{l}\text { Various } \\
\text { research } \\
\text { projects }\end{array}$ \\
\hline $\begin{array}{l}\text { Model Matching (map- } \\
\text { based positioning) }\end{array}$ & Order of $1-10 \mathrm{~cm}$ & Order of $1-3$ deg & $\sim 10 \mathrm{~m}$ & $\begin{array}{l}\text { Various } \\
\text { research } \\
\text { projects }\end{array}$ \\
\hline
\end{tabular}


Parts of this research were funded by a U.S. Department of Energy Grant DE-FG02-86NE37969. Parts of the text were adapted from refs. 3, 7, 20, and 22 .

\section{REFERENCES}

1. J. L. Farrell, Integrated Aircraft Navigation, Academic Press, New York, 1976.

2. R. H. Battin, An Introduction to the Mathematics and Methods of Astrodynamics, AIAA Education Series, New York, 1987.

3. H. R. Everett, Sensors for Mobile Robots: Theory and Application, A. K. Peters, Ltd., Wellesley, MA, 1995.

4. I. J. Cox, "Blanche-An experiment in guidance and navigation of an autonomous mobile Robot," IEEE Trans. Rob. Autom., 7(3), 193-204, 1991.

5. R. H. Byrne, P. R. Klarer, and J. B. Pletta, "Techniques for autonomous navigation." Sandia Report SAND920457, Sandia National Laboratories, Albuquerque, NM, 1992.

6. F. Chenavier and J. Crowley, "Position estimation for a mobile robot using vision and odometry," Proc. IEEE Int. Conf. Rob. Autom., Nice, France, 1992, pp. 2588-2593.

7. J. Borenstein, B. Everett, and L. Feng, Navigating Mobile Robots: Systems and Techniques, A. K. Peters, Ltd., Wellesley, MA, 1996.

8. J. Borenstein and L. Feng, "Measurement and correction of systematic odometry errors in mobile robots," IEEE J. Rob. Autom., 12(6), 1996, pp. 869-880.

9. Borenstein, J. and Evans, J., "The OmniMate Mobile Robot-Design, Implementation, and Experimental Results." 1997 IEEE International Conference on Robotics and Automation, Albuquerque, NM, Apr. 21-27, 1997.

10. J. Borenstein and L. Feng, "UMBmark - A method for measuring, comparing, and correcting dead-reckoning errors in mobile robots," Technical Report, The University of Michigan UM-MEAM-94-22, 1994.

11. J. Borenstein, "Internal correction of dead-reckoning errors with the compliant linkage vehicle," J. Rob. Syst., 12(4), 1995, pp. 257-273.

12. J. Borenstein, "The CLAPPER: A dual-drive mobile robot with internal correction of dead-reckoning errors," Proc. IEEE Int. Conf. Rob. Autom. (Video Proceedings), Nagoya, Japan, 1995.

13. TRC-Transitions Research Corp. (now under new name: "HelpMate Robotics Inc.-HRI"), Shelter Rock Lane, Danbury, CT 06810.

14. B. Barshan and H. F. Durrant-Whyte, "An inertial navigation system for a mobile robot." Proc. IEEE/RSJ Int. Conf. Intell. Rob. Syst., Yokohama, Japan, 1993, pp. 22432248.

15. B. Barshan and H. F. Durrant-Whyte, "Inertial navigation systems mobile robots," IEEE Trans. Rob. Autom. 11(3), 1995 pp. 328-342.

16. T. Dahlin and D. Krantz, "Low-cost, medium-accuracy land navigation system," Sensors, Feb., 26-34, 1988.

17. Andrew Corporation, 10500 W. 153rd Street, Orland Park, IL 60462.

18. $\mathrm{KVH}-\mathrm{KVH}$ Industries, $\mathrm{C} 100 \mathrm{Compass}$ Engine Product Literature, 110 Enterprise Center, Middletown, RI 02840 .
19. C. Cohen and F. Koss, "A comprehensive study of three object triangulation," Proc. SPIE Conf. Mobile Robots, Boston, MA, 1992, pp. 95-106.

19a. MTI-MTI Research, Inc., Chelmsford, MA.

20. J. Borenstein, B. Everett, and L. Feng, Navigating Mobile Robots: Systems and Techniques (CD-ROM Edition), A. K. Peters, Ltd., Wellesley, MA, 1996.

21. B. M. Gothard, R. D. Etersky, and R. E. Ewing, "Lessons learned on a low-cost global navigation system for the surrogate semi-autonomous vehicle," SPIE Proc., Vol. 2058, pp. 258-269, 1993.

22. R. H. Byrne, "Global positioning system receiver evaluation results," Sandia Report SAND93-0827, Sandia National Laboratories, Albuquerque, NM, 1993.

23. GPS Report. Phillips Business Information, Potomac, MD, 1992.

24. I. A. Getting, "The global positioning system," IEEE Spectrum, December, 36-47, 1993.

25. M. Jenkin, et al., "Global navigation for ARK," Proc. IEEE/RSJ Int. Conf. Intell. Rob. Syst., Yokohama, Japan, 1993, pp. 2165-2171.

26. S. Atiya and G. Hager, "Real-time vision-based robot localization," IEEE Trans. Rob. Autom., 9(6), 785-800, 1993.

27. R. Talluri and J. Aggarwal, "Position estimation techniques for an autonomous mobile robot-A review," in Handbook of Pattern Recognition and Computer Vision, World Scientific, Singapore, 1993, Chapter 4.4, pp. 769-801.

28. I. Fukui, "TV image processing to determine the position of a robot vehicle," Pattern Recognit., 14, 101109, 1981.

29. B. Lapin, "Adaptive position estimation for an automated guided vehicle," Proc. SPIE Conf. Mobile Rob., Boston, MA, Nov. 18-20, pp. 82-94.

30. Y. Mesaki and I. Masuda, "A new mobile robot guidance system using optical reflectors," Proc. IEEE/RSJ Int. Conf. Intell. Rob. Syst., Raleigh, NC, 1992, pp. 628-635.

31. S. Fleury and T. Baron, "Absolute external mobile robot localization using a single image," Proc. SPIE Conf. Mobile Rob., Boston, MA, 1992, pp. 131-143.

32. H. R. Everett, et al., "Real-world issues in warehouse navigation," Proc. SPIE Conf. Mobile Rob., Boston, MA, 1994, Vol. 2352.

33. C. DeCorte, "Robots train for security surveillance," Access Control, June, 37-38, 1994.

34. L. Gould, "Is off-wire guidance alive or dead?' Managing Autom., May, 38-40, 1990.

35. L. Feng, Y. Fainman, and Y. Koren, "Estimate of absolute position of mobile systems by optoelectronic processor," IEEE Trans. Man Mach. Cybern., 22(5), 954963, 1992.

36. W. D. Rencken, "Concurrent localization and map building for mobile robots using ultrasonic sensors," Proc. IEEE/RSJ Int. Conf. Intell. Rob. Syst., Yokohama, Japan, 1993, pp. 2192-2197.

37. W. D. Rencken, "Autonomous sonar navigation in indoor, unknown, and unstructured environments," Proc. IEEE/RSJ Int. Conf. Intell. Rob. Syst., Munich, Germany, 1994, pp. 127-134.

38. T. Edlinger and E. Puttkamer, "Exploration of an indoor 
environment by an autonomous mobile robot," Proc. IEEE/RSJ Int. Conf. Intell. Rob. Syst., Munich, Germany, 1994, pp. $1278-1284$

39. M. Buchberger, K. Jorg, and E. Puttkamer, "Laser radar and sonar based world modeling and motion control for fast obstacle avoidance of the autonomous mobile robot MOBOT-IV," Proc. IEEE Int. Conf. Rob. Autom., Atlanta, GA, 1993, pp. 534-540.

40. K. W. Jorg, Echtzeitfahige Multisensorintegration fur autonome mobile Roboter, B. .I. Wissenschaftsverlag, Mannheim, Leipzig, Wien, Zurich, 1994.

41. K. W. Jorg "World modeling for an autonomous mobile robot using heterogenous sensor information," Rob. Auton. Syst., 14, 159-170, 1995.

42. A. Kak, et al., "Hierarchical evidence accumulation in the PSEIKI system and experiments in model-driven mobile robot navigation," Uncertainty in Artificial Intelligence, Elsevier Science Publishers B. V., North-Holland, 1990, Vol. 5, pp. 353-369.

43. G. Schaffer, J. Gonzalez, and A. Stentz, "Comparison of two range-based pose estimators for a mobile robot," Proc. SPIE Conf. Mobile Rob., Boston, MA, 1992, pp. 661-667.

44. R. Hinkel and T. Knieriemen, "Environment perception with a laser radar in a fast moving robot," Symp. Rob. Control, Karlsruhe, Germany, 1988, pp. 68.1-68.7.

45. G. Weiss, C. Wetzler, and E. Puttkamer, "Keeping track of position and orientation of moving indoor systems by correlation of range-finder scans," 1994 Int. Conf. Intell. Rob. Syst., Munich, Germany, 1994, pp. 595-601. 
